\title{
Effect of combined treatment with Methotrexate and Non-steroidal anti-inflammatory drugs on plasma alpha-tocopherol level and Rheumatoid factor among Rheumatoid Arthritis patients
}

\author{
F Pervin ${ }^{1}$, MA Habib², N Ahmed ${ }^{3}$, *MMR Sardar ${ }^{4}$
}

\begin{abstract}
Background: Oxidative stress might play a significant role in the pathogenesis of Rheumatoid Arthritis. Traditional therapies of Rheumatoid Arthritis are governed by different NSAIDs which improve symptoms of Rheumatoid Arthritis. But addition of Methotrexate (MTX) to Non-steroidal anti-inflammatory drugs (NSAIDs) has been found to be extra beneficial by halting the disease process. Objectives: To evaluate the status of anti-oxidant alpha-tocopherol and rheumatoid factor before and after treatment with MTX and NSAIDs for two months in Rheumatoid Arthritis patients. Methods: This quasi-experimental study was carried out in the Department of Pharmacology and Therapeutics of Rajshahi Medical College, Rajshahi between the periods of January 2011 to December 2011. Total ten clinically diagnosed Rheumatoid Arthritis patients were enrolled in the study. Purposive sampling technique was used to select each study subject from medicine wards of Rajshahi Medical College Hospital. Alpha-tocopherol, an anti-oxidant in plasma was measured as marker of anti-oxidant defense. The patients were then treated with oral MTX at a dose of $10 \mathrm{mg}$ weekly and Indomethacin $150 \mathrm{mg}$ in three divided doses daily for 2 months. After 2 months of continuous aforementioned treatment, alpha-tocopherol levels were estimated again. Moreover qualitative assessment of rheumatoid factor was done. For statistical analysis, paired t-test was done. Results: After two months of treatment with Methotrexate and Indomethacin, plasma alpha-tocopherol levels were significantly higher $(P<0.05)$ in Rheumatoid Arthritis patients. However no significant change was observed in qualitative assessment of rheumatoid factors. Conclusion: From the findings of this study, it can be concluded that the endogenous alpha-tocopherol level increases even without any supplementation of alpha-tocopherol by combined treatment with MTX and Indomethacin in Rheumatoid Arthritis patients and thereby reduces oxidative stress. So alpha-tocopherol level is a better marker for early assessment of prognosis of Rheumatoid arthritis than Rheumatoid factor test.
\end{abstract}

Key words: Methotrexate, NSAIDs, Rheumatoid Arthritis, Alpha-tocopherol, Oxidative stress, Rheumatoid factor.

1. Dr. Farhana Pervin, Assistant Professor, Department of Pharmacology and Therapeutics, Sheikh Sayera Khatun Medical College, Gopalgonj.

2. Professor Dr. Md. Anwar Habib, Professor, Department of Pharmacology and Therapeutics and Principal, Rajshahi Medical College, Rajshahi.

3. Professor Dr. Nazimuddin Ahmed, Professor, Department of Pharmacology and Therapeutics, Rajshahi Medical College, Rajshahi.

4. Dr. Md. Mijanur Rahman Sardar, Assistant Professor, Department of Physiology. Khulna Medical College, Khulna. Email: mijanrmc@ hotmail.com. 
Introduction

Rheumatoid arthritis (RA) is a chronic multi-system disease of unknown etiology characterized by non-specific inflammation of peripheral joints with joint swelling, morning stiffness, destruction of articular tissue and joint deformities. It affects nearly one percent of the population world wide. ${ }^{1}$ The endogenous free radicals produced in the body are neutralized by endogenous antioxidants. If this balance is disturbed, it can produce oxidative stress. $^{2}$ A recent study indicated that increased oxidative stress and/or defective antioxidants status contribute to the pathology of Rheumatoid Arthritis. ${ }^{3}$

Rheumatoid Arthritis is treated with conventional therapies like non steroidal anti-inflammatory drugs (NSAIDs) such as indomethacin, naproxen, ibuprofen and disease modifying anti-rheumatic drugs (DMARDs) such as methotreaxate, sulphasalazine, hyroxychloroquine etc. $^{4}$

Methotrexate was first developed in the 1940 s as a specific antagonist of folic acid. This drug inhibits the proliferation of malignant cells, primarily by inhibiting the de novo synthesis of purines and pyrimidines. ${ }^{5}$ The demonstration in 1985 that low dose intermittent Methotrexate is a potent and effective therapy for Rheumatoid Arthritis led to a dramatic change in the way that Rheumatoid Arthritis are treated. ${ }^{6}$ Methotrexate is currently the most widely prescribed Drug Modifying Anti-rheumatic Drug ( DMARD) in Rheumatoid Arthritis due to it's high efficiency and rapid onset of action. In Rheumatoid Arthritis, it seems probable that its anti-inflammatory effect is more important than its anti-proliferative effect. ${ }^{7}$ It is believed that many DMARDs affect oxidative stress but there has been insufficient research to confirm such a relationship. ${ }^{8}$

Non steroidal anti-inflammatory drugs (NSAIDs) are commonly used for the treatment of Rheumatoid Arthritis. It suppresses inflammation in Rheumatoid Arthritis as demonstrated by relief of joint pain, swelling, tenderness and reduction of fever. It blocks prostaglandin synthesis by blocking cyclo-oxygenase enzyme. ${ }^{9}$ Recently a study suggested that NSAIDs have been associated with antioxidant property and improvement of the circulating antioxidants status on daily dosing in different inflammatory conditions. ${ }^{10}$

In 1922, Evans and Bishop observed that for normal reproduction in rats, a fat-soluble factor present in vegetable oils was required. This was named as vitamin E. In 1936, the compound was isolated and named as tocopherol. ${ }^{11}$ It exists in eight different forms, four tocopherols and four tocotrienols. ${ }^{12}$ It has many biological functions. The antioxidant function being the most important and best known. ${ }^{13}$ A low level of antioxidant status is associated with a high risk of developing Rheumatoid Arthritis. ${ }^{14}$ Patients with Rheumatoid Arthritis have been reported to have lower level of a variety of antioxidants including vitamin E. ${ }^{3}$ Adding a high dose of vitamin $E$ to the treatment regimen of the Rheumatoid disease suggested that by the end of second month, better control of disease was achieved. ${ }^{15}$

In Rheumatoid arthritis, auto-antibodies are formed against IgG. These auto-antibodies are called rheumatoid factors and are of IgM class. The diagnosis of Rheumatoid arthritis is supported by detecting rheumatoid factors. Patients have high titers of rheumatoid factor in serum especially during periods when their disease is most active. ${ }^{16}$ In combination with signs and symptoms, it can play a role in both diagnosis and disease prognosis. The higher the level of rheumatoid factor, greater the possibility of destructive articular disease. ${ }^{17}$

Treating Rheumatoid arthritis patients by either Methotrexate or NSAIDs possesses beneficial effect. Besides, combination of Methotrexate and NSAIDs may have potentiating effect. Thus the usefulness of these two drugs in Rheumatoid Arthritis could not be ignored.

We therefore planned to measure alpha-tocopherol levels and assess rheumatoid factors in order to evaluate any improvement 
in Rheumatoid Arthritis patients after combined treatment with Methotrexate and NSAIDs for two months.

\section{Methodology}

This quasi-experimental study was carried out in the department of Pharmacology and Therapeutics, Rajshahi Medical College, Rajshahi between the periods of January 2011 to December 2011. Ten clinically diagnosed adult Rheumatoid arthritis patients of both genders were enrolled in the study by using the criteria of American Rheumatism Association (ARA). Study subjects were selected by following purposive sampling technique from Rajshahi Medical College Hospital and the protocol of the study was approved by the Ethical Review Committee (ERC) of Rajshahi Medical College. All the subjects were free from Diabetes, Hypertension, Chronic liver and renal disease, Alcoholism and Smoking. Persons taking antioxidant therapy or DMARDs before the study were excluded from the study. Before recruitment, aim, benefit and procedure of the study was explained and informed written consent was taken from each study subject. Thorough physical examinations of all subjects were done. Assessment of joint tenderness was done by criteria mentioned in D'Cruz, 2007. Then under aseptic precaution, $4 \mathrm{ml}$ blood was taken from each subject in a test tube containing anti-coagulant di-potassium EDTA. Plasma was separated after centrifuging for 15 minutes at $3000 \mathrm{rpm}$ and plasma alpha-tocopherol levels were estimated and rheumatoid factor test was done. Then patients were given oral Methotrexate $(10 \mathrm{mg}$ weekly) and NSAID (Indomethacin $150 \mathrm{mg}$ daily in 3 divide doses) for two months. After two months, blood samples were taken again from each subject and plasma alpha-tocopherol levels were estimated and rheumatoid factor test was done.

Measurement of alpha-tocopherol levels were done by the method described by Baker and Frank, $1968 .^{18} \quad$ Moreover qualitative assessment of rheumatoid factors was done by slide latex agglutination test with diagnostic kit (Dialab).

Data were analyzed by computer using SPSS software program. Statistical analysis was done by paired t-test. P-value less than 0.05 was considered as significant.

\section{Results}

Table 01 shows baseline characteristics of study samples.

After combined treatment with Methotrexate and Indomethacin for two months, the plasma alpha-tocopherol levels of ten clinically diagnosed Rheumatoid arthritis patients were significantly increased $(P<0.05)$. (Table 02)

No significant change was observed in qualitative assessment of rheumatoid factor after treatment with Methotrexate and NSAIDs for two months (Table 03).

Table 01: Baseline characteristics of study subjects

Total number of samples $\quad 10$

Mean age in years

37

Sex

Male $(n, \%) \quad 1,10 \%$

Female $(n, \%) \quad 9,90 \%$

Joint tenderness

Grade-1 20\%

Grade-2 $\quad 50 \%$

Grade-3 $\quad 30 \%$

Mean duration of

morning stiffness in hours 
Table 02: Plasma alpha-tocopherl level in patients of Rheumatoid Arthritis before and after treatment with Methotrexate and Indomethacin $(n=10)$

\begin{tabular}{l|l|l}
\hline Parameter & $\begin{array}{l}\text { Before treatment } \\
(\mathbf{n = 1 0})\end{array}$ & $\begin{array}{l}\text { After treatment } \\
(\mathbf{n}=10)\end{array}$ \\
\hline $\begin{array}{l}\text { Alpha-tocopherol } \\
(\mathrm{mg} / \mathrm{dl})\end{array}$ & $2.78 \pm 0.97$ & $3.70 \pm 0.80^{*}$ \\
\hline
\end{tabular}

Data are expressed as mean $\pm S D$. Statistical analysis was done by paired t-test. Significant $=p<0.05, n=$ Total number of subjects.

Table 03: Comparison between Alpha-tocopherol and Rheumatoid factor level before and after treatment with Methotrexate and NSAIDs for two months $(n=10)$

\begin{tabular}{|c|c|c|c|}
\hline \multirow[t]{2}{*}{$\begin{array}{l}\text { Number of } \\
\text { patients }\end{array}$} & \multicolumn{2}{|c|}{$\begin{array}{l}\text { Alpha-tocopherol level (mg/dl) and Rheumatoid } \\
\text { factor test }\end{array}$} & \multirow[t]{2}{*}{ P-value } \\
\hline & $\begin{array}{l}\text { Before treatment } \\
\text { (BT) }\end{array}$ & $\begin{array}{l}\text { After treatment } \\
\qquad \text { (AT) }\end{array}$ & \\
\hline 1 & 2.7 (Positive) & 3.1(Positive) & \multirow{10}{*}{$\begin{array}{l}\text { BT vs AT changes } \\
\text { observed in Alpha- } \\
\text { tocopherol level but } \\
\text { no change in } \\
\text { Rheumatoid factor } \\
\text { test }\end{array}$} \\
\hline 2 & 2.7(Positive) & 3.7(Positive) & \\
\hline 3 & 2.7(Positive) & 5.1(Positive) & \\
\hline 4 & 02(Positive) & 4.1(Positive) & \\
\hline 5 & 01(Negative) & 2.7(Negative) & \\
\hline 6 & 2.1 (Negative) & 2.4(Negative) & \\
\hline 7 & 4.1(Negative) & 3.7(Negative) & \\
\hline 8 & 3.7(Negative) & 4.1(Negative) & \\
\hline 9 & 2.7(Negative) & 3.7(Negative) & \\
\hline 10 & 4.1(Negative) & 4.4(Negative) & \\
\hline
\end{tabular}

\section{Discussion}

Rheumatoid arthritis is a chronic, systemic inflammatory disease that is characterized by progressive joint destruction. ${ }^{19}$ Epidemiological studies have shown an inverse association between dietary intake of antioxidants and Rheumatoid Arthritis incidence and inverse associations between antioxidants levels and inflammation have been found. ${ }^{20}$ This disease is treated with NSAIDs such as indomethacin, naproxen, ibuprofen etc. Addition of DMARDs such as methotrexate, sulphasalazine, chloroquine etc. to NSAIDs have added advantages in protecting progressive joint destruction. ${ }^{4}$

In this study, we have found that plasma alpha-tocopherol level of ten clinically diagnosed Rheumatoid arthritis patients were significantly increased after treatment with Methotrexate and Indomethacin for two months. 
This finding is in agreement with Helmy et al. who revealed that combined treatment with Methotrexate, Sulphasalazine and Indomethacin for two months causes increased antioxidant alpha-tocopherol level in Rheumatoid Arthritis patients. ${ }^{15}$

Several researchers found that in Rheumatoid Arthritis patients, plasma antioxidants status were increased after conventional treatment for two to three months. They also reported that greater improvement of status of anti-oxidant status in Rheumatoid Arthritis patients after conventional treatment along with antioxidant supplementation. ${ }^{21,22}$

In this study, endogenous plasma alpha-tocopherol level was increased significantly after treatment even without any intervention of anti-oxidant supplementation. Alpha-tocopherol is fat-soluble; it is incorporated into cell membranes, which protects them from oxidative damage. Alpha-tocopherol is a major chain breaking antioxidant which acts by scavenging free radicals. ${ }^{23}$ In Rheumatoid Arthritis, alpha-tocopherol level is low because it has been used in reducing inflammatory products. ${ }^{24}$ Another study conducted by Shaabani et al. indicated that the decreased antioxidants status (Vitamin E, Beta-carotene) of Rheumatoid Arthritis patients has been explained by excessive need for antioxidants due to the inflammatory process itself. ${ }^{25}$ Recently a study suggested that NSAIDs have been associated with anti-oxidant property and improvement of the circulating anti-oxidant status on daily dosing in different inflammatory conditions. ${ }^{10}$

In this study, we observed that forty percent patients were rheumatoid factor positive and rests were sero-negative. Moreover no significant change was observed after treatment with Methotrexate and NSAIDs for two months in rheumatoid factor test. However no sero-negative patient became sero-positive after treatment. These findings are compatible with Anderson et al. ${ }^{26}$ It indicates that long-term treatment is required for sero-positive patients to become sero-negative or for any improvement of rheumatoid factor concentrations. As a result, rheumatoid factor test is not ideal for early assessment of prognosis of Rheumatoid arthritis patients. On the contrary, our observation indicates that two months treatment with Methotrexate and NSAIDs causes significant improvement of alpha-tocopherol levels in Rheumatoid arthritis patients. Consequently, we opine that measurement of alpha-tocopherol level should be used for early assessment of prognosis of Rheumatoid arthritis patients. Hence further study with greater number of patients should be done to evaluate the status of different anti-oxidants after treatment with Methotrexate and Indomethacin.

\section{Conclusion}

It can be concluded that combined treatment with Methotrexate and Indomethacin improve the anti-oxidant status without any intervention of antioxidant alpha-tocopherol in Rheumatoid Arthritis patients. Moreover Rheumatoid factor test is not suitable for early assessment of prognosis of Rheumatoid arthritis patients. However, this findings suggest the need for designing more clinical trials to find out the impact of Methotrexate and Indomethacin on the status of anti-oxidants in different stages of disease for the treatment of Rheumatoid Arthritis either alone or in combination.

\section{Conflict of interest: Nothing to declare.}

\section{References}

1. Bae SC, Kim SJ, Sung MK. Inadequate anti-oxidant nutrient intake and altered Plasma anti-oxidant status of rheumatoid arthritis patients. Journal of the American College of Nutrition. 2003; 22(4): 311-315.

2. Mahajan A. and Tandon VR. Anti -oxidants and Rheumatoid arthritis. J Indian Rheumatol Assoc. 2004; 12: 139-142. 
3. Karatas F, Ozates I, Canatan H, Halifeoglu I, Karatepe M, Colak R. Antioxidant status and lipid peroxidation in patients with rheumatoid arthritis. Indian $\mathrm{J}$ Med Res. 2003; 118: 178-181.

4. Lipsky PE. Disorders of the immune system, connective tissue, and joints. In: Fauci AS, Braunwald E, Kasper DL, Hauser SL, Longo DL, Jameson JL, Loscalzo J,(eds). Harison's Principles of Internal Medicine. 17th Edition. New York: The Mc Grew Hill Companies; 2008. 2(2): 2083-2092.

5. Chabner BA, Allegra CJ, Curt GA, Clendeninn NJ, Baram J, Koizumi S et al. Polyglutamation of methotrexate. J Clin Inves. 1985;76: 907-912.

6. Weinblatt ME, Coblyn JS, Fox DA, Fraser PA, Holdsworth DE, Glass DN et al. Efficacy of low dose methotrexate in Rheumatoid Arthritis. N Engl J Med. 1985; 312: 818-822.

7. Kamel MAE, Rayah ANA, Soliman ASM, Salama MA. Effect of Methotrexate treatment on markers of oxidative stress and IL-10 level in Rheumatoid Arthritis patients. Journal of the Medical Research Institute. 2006; 27(2):136-40.

8. Matyska - Piekarska E, Luszczewski A, Lacki J, Wawer I. Oxidative stress in Rheumatoid arthritis. Postepy Hig Med Dosw. 2006; 60: 617-623.

9. Furst DE and Ulrich RW. Nonsteroidal Anti - inflammatory Drugs, Disease Modifying Anti-rheumatic Drugs, Non opoid Analgesics, Drugs used in Gout. In: Katzung BG (ed). Basic and Clinical Pharmacology. 10th edition. Boston: The Mc Graw Hill companies; 2007.p. 583-584.

10. Nivsarkar $M$, Banerjee $A$, Shah D, Trivedi J, Patel M, Cherian B et al. Reduction in aluminium induced oxidative stress by meloxicam in rat brain. Iranian Biomedical Journal. 2006; 10(3): 151-155.

11. Satanarayana U. Biochemistry. 2nd edition. Kolkata: Books and Allied (P) Ltd;
2002. p.126

12. Burton GW, Ingold KU. Autooxidation of biological molecules. J Am. Chem. Soc. 1981; 103: 6472-6477.

13. Bell EF. History of vitamin $E$ in infant nutrition. American Journal of Clinical Nutrition. 1987; 46(1): 183-187.

14. Hagfors L, Leanderson P, Skoldstam L, Andersson J, Johansson G. Antioxidant intake, plasma antioxidants and oxidative stress in a randomized, controlled, Mediterranean dietary intervention study on patients with Rheumatoid arthritis. Nutrition Journal. 2003; 2(5): 1-11.

15. Helmy M, Shohayeb M, Helmy MH, ElBassiouni EA. Anti-oxidants as adjuvant therapy in rheumatoid disease: A preliminary study. Arzneimitteel- forschung. 2001; 51(4): 293-8.

16. Warren L. Review of Medical Microbiology and Immunology. 12th edition. USA: Mc Graw Hill companies; 2012. 534-543.

17. Turesson $C$, Jacobsson $L T H$, Sturfelt $G$, Matteson EL, Mathsson L, Ronnelid J. Rheumatoid factor and antibodies to cyclin citrullinated peptides are associated with severe extra-articular manifestations in Rheumatoid arthritis. Ann Rheum Dis. 2007; 66(1): 59-64.

18. Baker and Frank. Determination of serum vitamin E. In: Goenlock $\mathrm{AH}, \mathrm{Mc}$ Murray JR, Mc Lauchlan DM, (eds). Varleys Practical Clinical Biochemistry. 6th edition. London: Heinemann Medical Books; 1988. 901-903.

19. Nuki G, Ralston SH, Laqmani R. Disease of the connective tissue, joints and bones. In: Halett $C$, Chilvers ER, Hunter JAA, Boon NA, (eds). Davidson's Principles and Practice of Medicine. 18th Edition. Edinburgh: Churchill Livingstone; 1999.12: 835-848.

20. Hitchon CA and El-Gabalaway HS. Oxidation in rheumatoid arthritis. Arthritis Res Ther. 2004; 6: 265-278. 
21. Nourmohammadi I, Athari-Nikasm S, Vafa MR, Bidari A, Jazayeri A, Hoshyarrad A et al. Effect of antioxidant supplementations on oxidative stress in Rheumatoid Arthritis patients. Journal of Biological Sciences. 2010; 10(1): 63-66.

22. Jaswal S, Mehta HC, Sood AK, Kaur J. Antioxidant status in Rheumatoid arthritis and role of antioxidant therapy. Clinica Chemica Acta. 2003; 338: 123-129.

23. Traber MG and Stevens JF. "Free Radical Biology and Medicine-Vitamins C and $E$ : Beneficial effects from a mechanistic perspective". Free Radical Biology and Medicine. 2011; 51(5): 1000-13.

24. Walwadkar SD, Suryarkar AN, Katkam RV, Kumbar KM, Ankush RD. Oxidative stress and calcium-phosphorus levels in Rheumatoid Arthritis. Indian Journal of Clinical Biochemistry. 2006; 21(2): 134-137.
25. Shaabani, Y., Foroughi, M., Rastmanesh, R., Jamshidi, A., Tajik, N., Assadi, O., Assessment of antioxidant nutrition intake and malondialdehyde plasma level in Rheumatoid Arthritis. ARYA Atherosclerosis Journal. 2009; 5(1): 1-5.

26. Andersen PA, West SG, O'dell JR, Via CS $<$ Claypool PG, Kotzin BC. Weekly pulse Methotrexate in Rheumatoid arthritis: clinical and immunological effects in a randomized, double blind study. Ann Intern Med. 1985; 103(4): 489-496. 